\title{
Aurora-A kinase is differentially expressed in the nucleus and cytoplasm in normal Müllerian epithelium and benign, borderline and malignant serous ovarian neoplasms
}

Khaled J. Alkhateeb ${ }^{1+}$ (D), Jason E. Crane ${ }^{2 \dagger}$ (D) Müge Sak ${ }^{1,3}$ (D), Caitlin J. Jorgensen ${ }^{2}$, James P. O'Donnell², Cory T. Zumbar ${ }^{1}$ (D), Jason A. Wozniak ${ }^{2}$ (D), Clarence R. Salazar ${ }^{2}$, Anil V. Parwani ${ }^{4}$ (D) and Norman L. Lehman ${ }^{1,3,5,6^{*}}$ (D)

\begin{abstract}
Background: Aurora-A kinase is important for cellular proliferation and is implicated in the tumorigenesis of several malignancies, including of the ovary. Information regarding the expression patterns of Aurora-A in normal Müllerian epithelium as well as benign, borderline and malignant epithelial ovarian neoplasms is limited.

Methods: We investigated Aurora-A expression by immunohistochemistry in 15 benign, 19 borderline and 17 malignant ovarian serous tumors, and 16 benign, 8 borderline, and 2 malignant ovarian mucinous tumors. Twelve fimbriae from seven patients served as normal Müllerian epithelium controls. We also examined Aurora-A protein expression by western blot in normal fimbriae and tumor specimens.

Results: All normal fimbriae $(n=12)$ showed nuclear but not cytoplasmic Aurora-A immunoreactivity by immunohistochemistry. Benign ovarian tumors also showed strong nuclear Aurora-A immunoreactivity. Fortyeight percent $(13 / 27)$ of borderline tumors demonstrated nuclear Aurora-A immunoreactivity, while the remainder $(52 \%, 14 / 27)$ lacked Aurora-A staining. Nuclear Aurora-A immunoreactivity was absent in all malignant serous tumors, however, 47\% (8/17) demonstrated perinuclear cytoplasmic staining. These results were statistically significant when tumor class (benign/borderline/malignant) was compared to immunoreactivity localization or intensity (Fisher Exact Test, $p<0.01$ ). Western blot analysis confirmed the greater nuclear Aurora-A expression in control Müllerian epithelium compared to borderline and malignant tumors.
\end{abstract}

\footnotetext{
* Correspondence: Nllehman1@gmail.com

${ }^{\dagger}$ Khaled J. Alkhateeb and Jason E. Crane contributed equally to this work.

'Department of Pathology and Laboratory Medicine, The University of Louisville, Louisville, KY 40202, USA

${ }^{3}$ Department of Biochemistry and Molecular Genetics, The University of Louisville, Louisville, KY 40202, USA

Full list of author information is available at the end of the article
}

(c) The Author(s). 2021 Open Access This article is licensed under a Creative Commons Attribution 4.0 International License, which permits use, sharing, adaptation, distribution and reproduction in any medium or format, as long as you give appropriate credit to the original author(s) and the source, provide a link to the Creative Commons licence, and indicate if changes were made. The images or other third party material in this article are included in the article's Creative Commons licence, unless indicated otherwise in a credit line to the material. If material is not included in the article's Creative Commons licence and your intended use is not permitted by statutory regulation or exceeds the permitted use, you will need to obtain permission directly from the copyright holder. To view a copy of this licence, visit http://creativecommons.org/licenses/by/4.0/ The Creative Commons Public Domain Dedication waiver (http://creativecommons.org/publicdomain/zero/1.0/) applies to the data made available in this article, unless otherwise stated in a credit line to the data. 
Conclusion: Aurora-A kinase is differentially expressed across normal Müllerian epithelium, benign and borderline serous and mucinous ovarian epithelial neoplasms and malignant serous ovarian tumors., with nuclear expression of unphosphorylated Aurora-A being present in normal and benign neoplastic epithelium, and lost in malignant serous neoplasms. Further studies of the possible biological and clinical implications of the loss of nuclear AuroraA expression in ovarian tumors, and its role in ovarian carcinogenesis are warranted.

Keywords: Ovarian, Aurora-a, Nuclear, Cytoplasmic, Differential localization, Immunohistochemistry

\section{Background}

Aurora-A is a serine-threonine kinase involved in cell cycle progression and mitosis $[1,2]$. Aurora-A misexpression may lead to mitotic errors and genomic instability [2]. Its overexpression has been implicated in the tumorigenesis of several malignant neoplasms, including hematolymphoid lesions [3], gliomas [4, 5], medulloblastomas [6], and carcinomas of the breast [7], gastrointestinal tract $[8,9]$ and ovary [10].

In normal tissues, Aurora-A directly interacts and colocalizes with the nuclear pore complex in a transient manner at the metaphase-anaphase transition during mitosis. Aberrance of nuclear pore complex components prevents Aurora-A translocation into the nucleus and has been shown to cause polyploidy and mitotic catastrophe, potentially increasing the risk of chromosomal translocations and mutations during early stages of cancer development [11, 12].

In ovarian carcinoma, Aurora-A mediates cell migration and adhesion [13]. Inhibition of Aurora-A prevents the epithelial-to-mesenchymal transition, which is correlated with more aggressive tumor progression and metastasis [14]. Aurora-A promotes cell cycle progression and genomic instability through repression of $\mathrm{p} 21, \mathrm{pRb}$, and BRCA2 [15], and overexpression has been associated with tumor progression and poor prognosis [16]. In the current study, we evaluated the differential nuclear and cytoplasmic expression of Aurora-A in benign, borderline and malignant serous and mucinous ovarian tumors using immunohistochemical and western blot analyses.

\section{Methods}

\section{Tumors and control Normal tissue}

The use of human tissues was approved by the Henry Ford Health System Institutional Review Board. Using the search terms "serous cystadenoma, serous borderline tumor, serous carcinoma, mucinous cystadenoma, mucinous borderline tumor, and mucinous carcinoma" we identified 84 ovarian neoplasms in our pathology case files. Cases signed out as mixed serous and mucinous neoplasms were excluded from the study. Seventy-seven cases remained: 15 benign serous tumors, 19 borderline serous tumors, 17 malignant serous tumors (including 16 high-grade serous carcinomas and 1 low-grade serous carcinoma), 16 benign mucinous tumors, 8 borderline mucinous tumors and 2 primary ovarian mucinous adenocarcinomas. Tumor diagnoses were confirmed by consensus review by three pathologists (KJA, JEC, NLL). Additionally, 12 fimbriae from 7 patients were included as normal tissue controls.

\section{Immunohistochemistry}

Four-micron thick paraffin-embedded sections were incubated with anti-human Aurora-A antibodies (Dako North America, Inc., 1:500 dilution). Slides received heat induced epitope retrieval (HIER) using Envision FLEX Target Retrieval Solution Low pH, Citrate Buffer pH 6.1 (TRL). HIER was performed in a DAKO PT LINK Chamber. In a DAKO LINK Autostainer, endogenous peroxide was blocked using 3\% hydrogen peroxide for $5 \mathrm{~min}$. The primary antibody was incubated for $20 \mathrm{~min}$. Visualization was achieved via a $15 \mathrm{~min}$ incubation of FLEX + Rabbit Linker, followed by a 20 min incubation of FLEX HRP (Dextran coupled with peroxidase and goat secondary antibody against rabbit and mouse immunoglobulins), and a 10 min incubation with DAB Chromogen (3,3' -diaminobenzidine tetrahydrochloride). TRIS buffer washes were performed between each incubation. Slides were counterstained with Mayer's Hematoxylin for $5 \mathrm{~min}$ and washed for $15 \mathrm{~min}$ in tap water. Interpretation of staining pattern and intensity was performed independently by two of the study pathologists (JEC, NLL) and a consensus was then reached. Positive staining was defined as greater than or equal $5 \%$ of tumor cell immunoreactivity. The immunoreactivity localization was recorded as absent, cytoplasmic, or nuclear immunoreactivity. The intensity of immunolabeling was scored on a scale of 0 to $3(0$, negative, 1 , weak, 2 , moderate, 3 , strong).

\section{Tissue lysates and Western blotting}

Samples of normal fimbriae and ovarian tumors were obtained from fresh surgical specimens, snap frozen in liquid nitrogen and stored in -80 degrees Celsius. Frozen tissue was homogenized on ice and processed into nuclear and cytosolic fractions as previously described [17]. Protease inhibitors (aprotinin (Sigma, St. Louis, $\mathrm{MO}$ ), leupeptin, pepstatin A, chymostatin, and AEBSF (MP Biomedicals, Solon, $\mathrm{OH})$ ) and $1 \mu \mathrm{M}$ DTT were added to all lysis buffers. Protein concentration was determined by the Pierce BCA method (Thermo Fisher 
Scientific, Waltham, MA). Nuclear and cytosolic fractions $(20 \mu \mathrm{g}$ total protein per lane) were electrophoresed on $10 \%$ polyacrylamide gels and electrotransferred to PVDF membranes (Millipore, Billerica, MA). Blocking was performed with $4 \%$ dried milk in TBST. Membranes were incubated with anti-human Aurora-A antibodies (Abcam, ab13824, 1:500), anti-human phospho- $\mathrm{Thr}^{288}$. Aurora-A (Abcam, ab58494, 1:500) or anti-human $\beta$ actin (Sigma, A2228, 1:5000) antibodies, followed by incubation with goat anti-mouse IgG-HRP (Santa Cruz Biotechnologies, Santa Cruz, CA) secondary antibody. Blots were developed with Pierce ECL (Thermo Fisher Scientific, Waltham, MA) and exposed to X-ray film.

\section{Statistical analysis}

Using VassarStats online statistical software (http:// www.vassarstats.net/), Fisher exact test was used to determine the significance of differences in Aurora-A immunohistochemical stain localization and intensity between benign, borderline and malignant ovarian neoplasms. A $p$-value of less than 0.05 was considered statistically significant.

\section{Results}

\section{Immunohistochemistry}

There were 26 cases (34\%) that were negative for Aurora-A by immunohistochemistry (IHC), 8 cases (10\%) with cytoplasmic immunoreactivity, and 43 cases (56\%) with nuclear immunoreactivity. All 12 normal fimbriae showed nuclear Aurora-A immunoreactivity. Almost all benign serous and mucinous tumors showed moderate to strong nuclear staining (Fig. 1). Weak nonspecific cytoplasmic "blush-like" staining was present in some of the normal control and benign cases; however, no convincing perinuclear cytoplasmic staining was demonstrated. Nuclear immunoreactivity was present in 42 and $62.5 \%$ of serous and mucinous borderline tumors, respectively. The remaining borderline tumors (52\%) lacked any Aurora-A immunoreactivity (Fig. 2). In contrast, nuclear immunoreactivity was absent in all 17 malignant serous tumors. One of two mucinous carcinomas showed weak nuclear staining, however data from only two samples is insufficient to draw any conclusions from. Forty-two percent (8/19) of the malignant tumors demonstrated perinuclear cytoplasmic immunoreactivity for Aurora-A (Table 1), ranging from weak to strong (Table 2) (Fig. 3). Using Fisher exact test, the results were found to be highly statistically significant when tumor class (benign/borderline/malignant) was analyzed against immunoreactivity pattern (absent/cytoplasmic/ nuclear) or intensity (weak, moderate, strong) $(p<0.01)$. The only exception was when comparing Aurora-A staining intensity between all serous and mucinous borderline and malignant tumors. (Table 3).

\section{Western blotting}

Western blotting for Aurora-A protein confirmed its predominantly cytoplasmic localization in malignant serous carcinomas, as well as in a borderline serous tumor, and less so a borderline mucinous tumor. In contrast, a near equal nuclear and cytoplasmic distribution of Aurora-A was observed in normal fimbriae (Fig. 4, Supplemental Fig. 1). Unlike total Aurora-A protein, phospho-Thr ${ }^{28}$-Aurora-A was heavily concentrated in the nuclear compartment of benign, borderline, and malignant serous ovarian tumors, as a whole. (Fig. 4, Supplemental Fig. 1).

\section{Discussion}

Because of the complex structure and natural history of the adult ovary it is often difficult to demonstrate normal benign ovarian epithelium as a control for immunohistochemical studies and essentially impossible to isolate sufficient amounts for western blotting. Benign Müllerian epithelium, most readily available in normal fallopian tube fimbriae, shows gene expression patterns similar to serous ovarian tumors [18] and is a good normal control for serous tumors, at least some of which arise in the distal fallopian tube $[19,20]$.

Aurora-A expression has been reported to be an independent prognostic factor for progression-free survival in ovarian carcinoma [21]. One study correlated nuclear and cytoplasmic Aurora-A overexpression in ovarian serous carcinoma with shorter survival, high grade, high proliferation index, and aberrant p53 expression [22]. Interestingly, that study also found that only cytoplasmic Aurora-A expression was associated with tumor cell aneuploidy, which was a strong predictor of poor outcome. Yet the biology of Aurora-A is complex, and it may also possibly function as a tumor suppressor [4].

We found that benign fimbriae had the highest nuclear to cytoplasmic ratio of total Aurora-A based on western blotting. Benign serous and mucinous ovarian tumors also showed strong nuclear immunoreactivity by immunohistochemistry. Borderline tumors tended to show nuclear immunoreactivity like benign tumors, however it was generally weaker, and they sometimes lacked nuclear staining like malignant tumors. In contrast, none of the malignant serous tumors we examined demonstrated nuclear Aurora-A immunoreactivity. Unlike benign and borderline tumors, malignant serous tumors sometimes showed cytoplasmic immunoreactivity for Aurora-A. This is in line with previous work showing low Emi1 expression in the cytoplasm of neoplastic cells in some serous ovarian carcinomas through immunohistochemical analysis [23], as Emil protects Aurora-A from degradation by the anaphase promoting complex/ cyclosome [24]. Notably, the differential localization of 


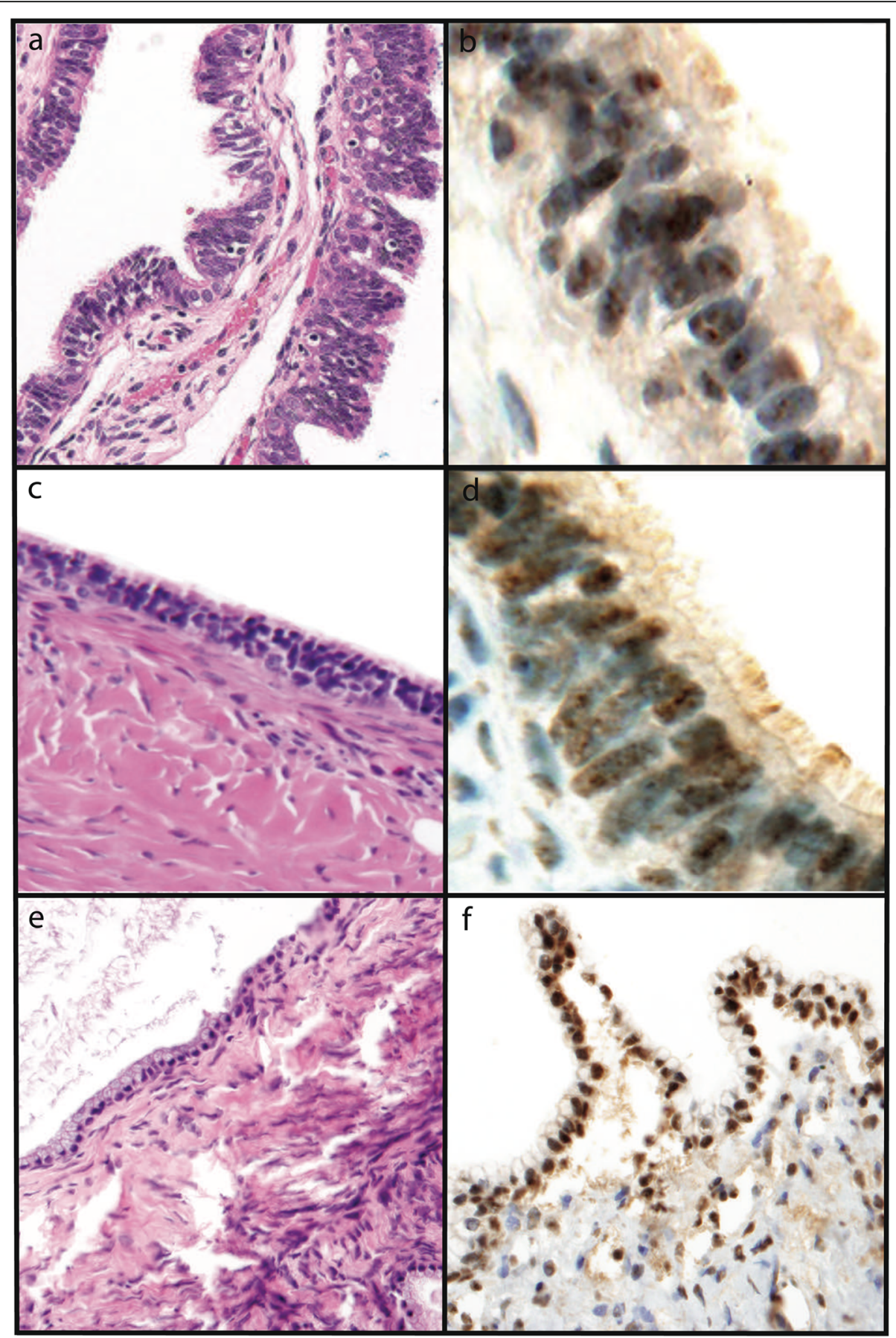

Fig. $1 \mathrm{H} \& \mathrm{E}$ stains and Aurora-A immunohistochemistry in normal tissue and benign neoplasms. Hematoxylin and eosin (H\&E) stains and Aurora-A nuclear immunoreactivity in control normal Müllerian epithelium (a, 200x original magnification, and b, 400x original magnification) and benign serous (c, 200x original magnification, and d, 400x original magnification) and mucinous cystadenomas (e and f, 200x original magnification)

other mitotic spindle proteins in benign and malignant tissue has also been reported [11].

Although nuclear total Aurora-A expression was not detected in serous carcinoma by immunohistochemistry, nuclear phospho- $\mathrm{Thr}^{288}$-Aurora-A expression was identified in serous carcinomas by western blotting. It is possible that phospho- $\mathrm{Thr}^{288}$-Aurora-A is less efficiently recognized by the "total' anti-Aurora-A antibody, is much less abundant compared to total Aurora-A, or both. Nevertheless, there appears to be decreased accumulation of total Aurora-A in the nucleus of serous ovarian carcinomas and often increased accumulation in 


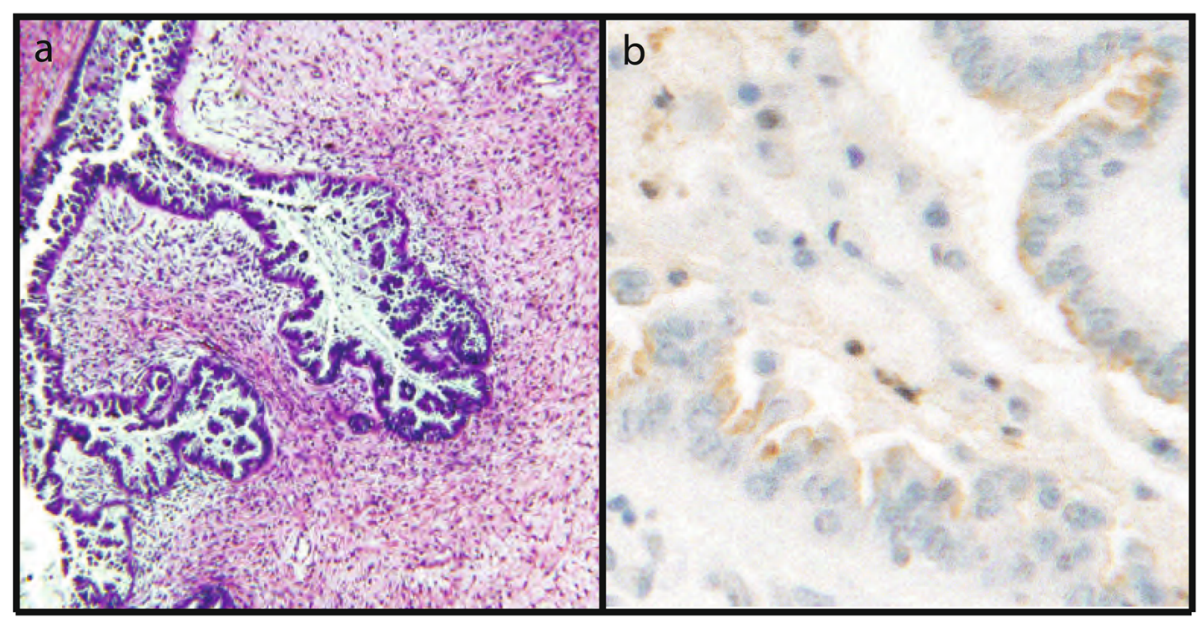

Fig. $2 \mathrm{H \& E}$ and absence of Aurora-A immunoreactivity in a borderline serous tumor (a, 100x original magnification, b 400x original magnification)

the cytoplasm, where it is known to perform many of its pro-mitotic functions [25]. This finding was demonstrated by both IHC and western blotting. It must be remembered that negative immunohistochemistry does not mean the protein is absent from the cell, but that it is not detectable by this relatively insensitive method.

Phosphorylation of Aurora-A at $\mathrm{Thr}^{288}$ correlates with activation of its kinase activity. The nuclear and cytoplasmic localization of Aurora-A, however, does not appear to be dependent on its kinase activation [26]. Furthermore, Aurora-A may be able to perform functions inside the nucleus that are not related to its kinase domain, including possibly acting as a transcriptional coactivator [27]. This should not be surprising given that although there is a large degree of homology between

Table 1 Aurora-A staining localization for each tumor type

\begin{tabular}{llllll}
\hline Tissue & Type & Absent & Cytoplasmic & Nuclear & Total \\
\hline Fimbriae & Control & 0 & 0 & 12 & 12 \\
Serous Tumors & Benign & 1 & 0 & 14 & 15 \\
& Borderline & 11 & 0 & 8 & 19 \\
& Malignant & 9 & 8 & 0 & 17 \\
& Total & 21 & 8 & 22 & 51 \\
Mucinous Tumors & Benign & 1 & 0 & 15 & 16 \\
& Borderline & 3 & 0 & 5 & 8 \\
& Malignant & 1 & 0 & 1 & 2 \\
All Tumors & Total & 5 & 0 & 21 & 26 \\
& Benign & 2 & 0 & 29 & 31 \\
& Borderline & 14 & 0 & 13 & 27 \\
& Malignant & 10 & 8 & 1 & 19 \\
& Total & 26 & 8 & 43 & 77 \\
\hline
\end{tabular}

the catalytic domains of all human Aurora proteins, they perform unique roles inside the cell for which their precise localization is a key factor [28]. Indeed, the functional differences between Aurora-A and Aurora-B are determined by their spatial compartmentalization [29]. This suggests that spatial regulation could be an important factor in the oncogenic role of Aurora-A. Increased cytoplasmic staining of Aurora-A in malignant cells may be due to increased Aurora-A transcription, thus overwhelming its nuclear transport and leading to cytoplasmic accumulation and decreased nuclear accumulation of unphosphorylated Aurora-A.

Negative nuclear Aurora-A expression in malignant and some borderline tumors may have potential implications in the biology of serous ovarian tumors. The fact

Table 2 Aurora-A staining intensity for each tumor type

\begin{tabular}{|c|c|c|c|c|c|c|}
\hline Tissue & Type & Absent & $\begin{array}{l}\text { Weak } \\
\text { (1) }\end{array}$ & $\begin{array}{l}\text { Moderate } \\
\text { (2) }\end{array}$ & $\begin{array}{l}\text { Strong } \\
\text { (3) }\end{array}$ & Total \\
\hline Fimbriae & Control & 0 & 2 & 5 & 5 & 12 \\
\hline \multirow{4}{*}{$\begin{array}{l}\text { Serous } \\
\text { Tumors }\end{array}$} & Benign & 1 & 1 & 5 & 8 & 15 \\
\hline & Borderline & 11 & 6 & 2 & 0 & 19 \\
\hline & Malignant & 9 & 5 & 1 & 2 & 17 \\
\hline & Total & 21 & 12 & 8 & 10 & 51 \\
\hline \multirow{4}{*}{$\begin{array}{l}\text { Mucinous } \\
\text { Tumors }\end{array}$} & Benign & 1 & 1 & 8 & 6 & 16 \\
\hline & Borderline & 3 & 2 & 1 & 2 & 8 \\
\hline & Malignant & 1 & 1 & 0 & 0 & 2 \\
\hline & Total & 5 & 4 & 9 & 8 & 26 \\
\hline \multirow[t]{4}{*}{ All Tumors } & Benign & 2 & 2 & 13 & 14 & 31 \\
\hline & Borderline & 14 & 8 & 3 & 2 & 27 \\
\hline & Malignant & 10 & 6 & 1 & 2 & 19 \\
\hline & Total & 26 & 16 & 17 & 18 & 77 \\
\hline
\end{tabular}




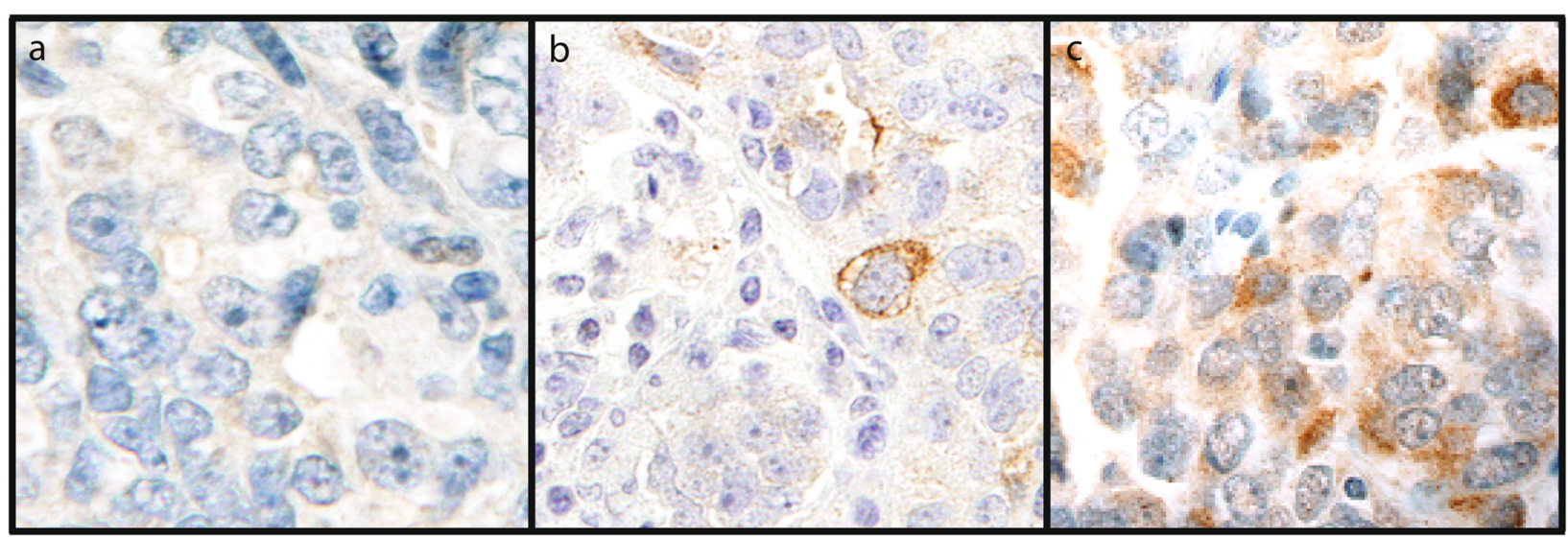

Fig. 3 Aurora-A immunoreactivity in high-grade serous carcinoma. High-grade serous carcinomas with negative (a), weak (b) and strong (c) cytoplasmic Aurora-A immunoreactivity (400x original magnification)

that inhibition of Aurora-A has been found to synergistically enhance the cytotoxicity of taxanes [30-32] and carboplatin [33, 34], two of the most important chemotherapeutics for ovarian cancers [35], provides justification for further study of the possible roles of Aurora-A in the diagnosis and treatment of ovarian neoplasms.

Table 3 Results of Fisher's Exact Test for comparisons of AuroraA immunoreactivity localization and intensity between different tumor categories

\begin{tabular}{|c|c|}
\hline Tumor Categories & $\begin{array}{l}P \text { value (Fishers } \\
\text { Exact Test) }\end{array}$ \\
\hline $\begin{array}{l}\text { Aurora-A Localization in all Benign vs. Malignant } \\
\text { Tumors }\end{array}$ & $9.340 \mathrm{E}-11$ \\
\hline $\begin{array}{l}\text { Aurora-A Localization in all Borderline vs. } \\
\text { Malignant Tumors }\end{array}$ & 0.00002 \\
\hline $\begin{array}{l}\text { Aurora-A Localization in all Benign vs. Borderline } \\
\text { Tumors }\end{array}$ & 0.00022 \\
\hline $\begin{array}{l}\text { Aurora-A Intensity in all Benign vs. Malignant } \\
\text { Tumors }\end{array}$ & 0.000005 \\
\hline $\begin{array}{l}\text { Aurora-A Intensity in all Borderline vs. Malignant } \\
\text { Tumors }\end{array}$ & 0.9 \\
\hline $\begin{array}{l}\text { Aurora-A Intensity in all Benign vs. Borderline } \\
\text { Tumors }\end{array}$ & 0.0000014 \\
\hline $\begin{array}{l}\text { Aurora-A Localization in Benign vs. Malignant } \\
\text { Serous Tumors }\end{array}$ & $3.181 \mathrm{E}-8$ \\
\hline $\begin{array}{l}\text { Aurora-A Localization in Borderline vs. Malignant } \\
\text { Serous Tumors }\end{array}$ & 0.00006 \\
\hline $\begin{array}{l}\text { Aurora-A Localization in Benign vs. Borderline } \\
\text { Serous Tumors }\end{array}$ & 0.003 \\
\hline $\begin{array}{l}\text { Aurora-A Intensity in Benign vs. Malignant } \\
\text { Serous Tumors }\end{array}$ & 0.001 \\
\hline $\begin{array}{l}\text { Aurora-A Intensity in Borderline vs. Malignant } \\
\text { Serous Tumors }\end{array}$ & 0.62 \\
\hline $\begin{array}{l}\text { Aurora-A Intensity in Benign vs. Borderline } \\
\text { Serous Tumors }\end{array}$ & 0.00002 \\
\hline
\end{tabular}

\section{Conclusion}

Aurora-A kinase is differentially expressed across normal Müllerian epithelium, benign and borderline serous and mucinous ovarian epithelial neoplasms and malignant serous ovarian tumors. Normal Müllerian epithelium as well as benign ovarian neoplasms show distinct nuclear expression of Aurora-A on both IHC and western blot, while malignant serous ovarian tumors demonstrate loss

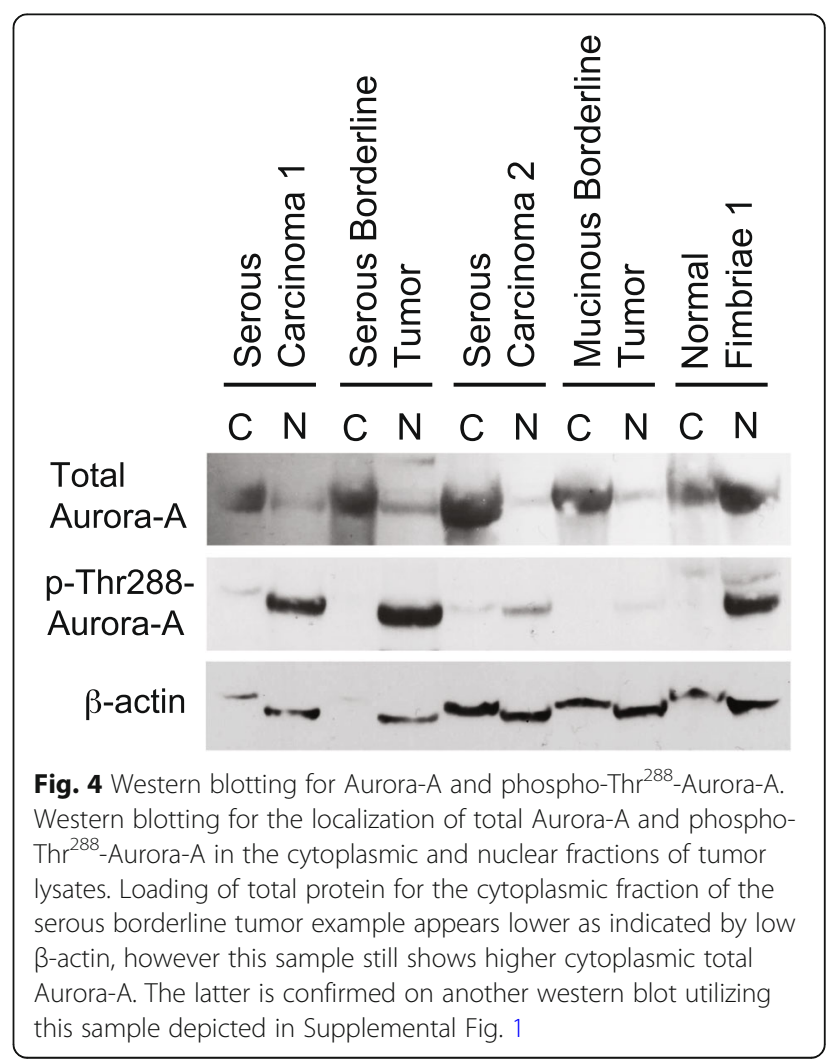


of nuclear expression, but showed perinuclear cytoplasmic immunoreactivity in approximately $50 \%$ of cases on IHC. Further studies are warranted in order to further understand the possible biological and clinical implications of the loss of non-phospho- $\mathrm{Thr}^{288}$-Aurora-A nuclear expression in ovarian tumors, and its role in ovarian carcinogenesis.

\section{Supplementary Information}

The online version contains supplementary material available at https://doi. org/10.1186/s13000-021-01158-4.

Additional file 1: Supplemental Figure 1. Additional western blot of neoplasm samples used in Fig. 4 for total Aurora-A showing similar results (a). Separate western blots of normal fimbriae for total Aurora-A showing approximately equal nuclear and cytoplasmic accumulation.

\section{Acknowledgements}

The authors thank Kathleen Roszka for technical assistance, and Dr. Brie Kezlarian for assistance with slides used for this project. The authors also thank Dr. Daniel Schultz at Henry Ford Health System, Detroit, for statistical assistance with this study.

\section{Authors' contributions}

All authors contributed to the study conception and design. Materia preparation, data collection and analysis were performed by all authors. The first draft of the manuscript was written by JEC, and all authors commented on previous versions of the manuscript. All authors read and approved the final manuscript.

\section{Funding}

This work was supported in part by National institutes of Health $(\mathrm{NIH})$ grants K08 NS45077 and R01 NS081125 (NLL).

\section{Availability of data and materials}

Not applicable

\section{Declarations}

\section{Ethics approval and consent to participate}

The use of human tissues was approved by the Henry Ford Health System Institutional Review Board. Not applicable

\section{Consent for publication}

Not applicable.

\section{Competing interests}

The authors declare that they have no competing interests.

\section{Author details}

'Department of Pathology and Laboratory Medicine, The University of Louisville, Louisville, KY 40202, USA. ²Department of Pathology and Laboratory Medicine, Henry Ford Hospital Detroit, Detroit, MI 48202, USA ${ }^{3}$ Department of Biochemistry and Molecular Genetics, The University of Louisville, Louisville, KY 40202, USA. ${ }^{4}$ Department of Pathology, Ohio State University, Columbus, OH 43210, USA. ${ }^{5}$ Department of Pathology, Wayne State University, Detroit, MI 48201, USA. ${ }^{6}$ The Brown Cancer Center, The University of Louisville, Louisville, KY 40202, USA.

Received: 11 June 2021 Accepted: 25 September 2021

Published online: 27 October 202

\section{References}

1. Katayama H, Sasai K, Kawai H, Yuan ZM, Bondaruk J, Suzuki F, et al. Phosphorylation by aurora kinase a induces Mdm2-mediated destabilization and inhibition of p53. Nat Genet. 2004;36(1):55-62.
2. Lehman NL, Tibshirani R, Hsu JY, Natkunam Y, Harris BT, West RB, et al. Oncogenic regulators and substrates of the anaphase promoting complex/ cyclosome are frequently overexpressed in malignant tumors. Am J Pathol. 2007;170(5):1793-805.

3. Kanagal-Shamanna R, Lehman NL, O'Donnell JP, Lim MS, Schultz DS, Chitale DA, et al. Differential expression of aurora-a kinase in T-cell lymphomas. Mod Pathol. 2013;26(5):640-7.

4. Lehman NL, O'Donnell JP, Whiteley LJ, Stapp RT, Lehman TD, Roszka KM, et al. Aurora a is differentially expressed in gliomas, is associated with patient survival in glioblastoma and is a potential chemotherapeutic target in gliomas. Cell Cycle. 2012;11(3):489-502.

5. Van Brocklyn JR, Wojton J, Meisen WH, Kellough DA, Ecsedy JA, Kaur B, et al. Aurora-a inhibition offers a novel therapy effective against intracranial glioblastoma. Cancer Res. 2014;74(19):5364-70

6. Neben K, Korshunov A, Benner A, Wrobel G, Hahn M, Kokocinski F, et al. Microarray-based screening for molecular markers in medulloblastoma revealed STK15 as independent predictor for survival. Cancer Res. 2004;64(9): 3103-11.

7. Tanaka T, Kimura M, Matsunaga K, Fukada D, Mori H, Okano Y. Centrosomal kinase AIK1 is overexpressed in invasive ductal carcinoma of the breast. Cancer Res. 1999;59(9):2041-4.

8. Li D, Zhu J, Firozi PF, Abbruzzese JL, Evans DB, Cleary K, et al. Overexpression of oncogenic STK15/BTAK/Aurora a kinase in human pancreatic cancer. Clin Cancer Res. 2003;9(3):991-7.

9. Takahashi T, Futamura M, Yoshimi N, Sano J, Katada M, Takagi Y, et al. Centrosomal kinases, HsAIRK1 and HsAIRK3, are overexpressed in primary colorectal cancers. Jpn J Cancer Res. 2000;91(10):1007-14.

10. Gritsko TM, Coppola D, Paciga JE, Yang L, Sun M, Shelley SA, et al. Activation and overexpression of centrosome kinase BTAK/Aurora-a in human ovarian cancer. Clin Cancer Res. 2003:9(4):1420-6.

11. Burum-Auensen $E$, De Angelis PM, Schjolberg AR, Kravik KL, Aure M, Clausen OP. Subcellular localization of the spindle proteins Aurora a, Mad2, and BUBR1 assessed by immunohistochemistry. J Histochem Cytochem. 2007; 55(5):477-86.

12. Kobayashi A, Hashizume C, Dowaki T, Wong RW. Therapeutic potential of mitotic interaction between the nucleoporin Tpr and aurora kinase a. Cell Cycle. 2015;14(9):1447-58.

13. Do TV, Xiao F, Bickel LE, Klein-Szanto AJ, Pathak HB, Hua X, et al. Aurora kinase a mediates epithelial ovarian cancer cell migration and adhesion. Oncogene. 2014;33(5):539-49.

14. Ding YH, Zhou ZW, Ha CF, Zhang XY, Pan ST, He ZX, et al. Alisertib, an Aurora kinase a inhibitor, induces apoptosis and autophagy but inhibits epithelial to mesenchymal transition in human epithelial ovarian cancer cells. Drug Des Devel Ther. 2015;9:425-64.

15. Yang G, Chang B, Yang F, Guo X, Cai KQ, Xiao XS, et al. Aurora kinase a promotes ovarian tumorigenesis through dysregulation of the cell cycle and suppression of BRCA2. Clin Cancer Res. 2010;16(12):3171-81.

16. Landen CN Jr, Lin YG, Immaneni A, Deavers MT, Merritt WM, Spannuth WA, et al. Overexpression of the centrosomal protein Aurora-a kinase is associated with poor prognosis in epithelial ovarian cancer patients. Clin Cancer Res. 2007:13(14):4098-104.

17. Filiano AJ, Bailey CD, Tucholski J, Gundemir S, Johnson GV. Transglutaminase 2 protects against ischemic insult, interacts with HIF1beta, and attenuates HIF1 signaling. FASEB J. 2008;22(8):2662-75.

18. Marquez RT, Baggerly KA, Patterson AP, Liu J, Broaddus R, Frumovitz M, et al. Patterns of gene expression in different histotypes of epithelial ovarian cancer correlate with those in normal fallopian tube, endometrium, and colon. Clin Cancer Res. 2005;11(17):6116-26.

19. Crum CP, Drapkin R, Miron A, Ince TA, Muto M, Kindelberger DW, et al. The distal fallopian tube: a new model for pelvic serous carcinogenesis. Curr Opin Obstet Gynecol. 2007;19(1):3-9.

20. Lee Y, Miron A, Drapkin R, Nucci MR, Medeiros F, Saleemuddin A, et al. A candidate precursor to serous carcinoma that originates in the distal fallopian tube. J Pathol. 2007;211(1):26-35.

21. Mendiola M, Barriuso J, Marino-Enriquez A, Redondo A, Dominguez-Caceres A, Hernandez-Cortes $G$, et al. Aurora kinases as prognostic biomarkers in ovarian carcinoma. Hum Pathol. 2009;40(5):631-8.

22. Lassus $H$, Staff $S$, Leminen A, Isola J, Butzow R. Aurora-a overexpression and aneuploidy predict poor outcome in serous ovarian carcinoma. Gynecol Oncol. 2011:120(1):11-7. 
23. Gutgemann I, Lehman NL, Jackson PK, Longacre TA. Emi1 protein accumulation implicates misregulation of the anaphase promoting complex/cyclosome pathway in ovarian clear cell carcinoma. Mod Pathol. 2008;21(4):445-54.

24. Lehman NL, Verschuren EW, Hsu JY, Cherry AM, Jackson PK. Overexpression of the anaphase promoting complex/cyclosome inhibitor Emi1 leads to tetraploidy and genomic instability of p53-deficient cells. Cell Cycle. 2006; 5(14):1569-73.

25. Marumoto T, Zhang D, Saya H. Aurora-a - a guardian of poles. Nat Rev Cancer. 2005;5(1):42-50.

26. Rannou Y, Troadec MB, Petretti C, Hans F, Dutertre S, Dimitrov S, et al. Localization of aurora a and aurora B kinases during interphase: role of the N-terminal domain. Cell Cycle. 2008;7(19):3012-20.

27. Zheng F, Yue C, Li G, He B, Cheng W, Wang X, et al. Nuclear AURKA acquires kinase-independent transactivating function to enhance breast cancer stem cell phenotype. Nat Commun. 2016;7:10180.

28. Carmena M, Earnshaw WC. The cellular geography of aurora kinases. Nat Rev Mol Cell Biol. 2003;4(11):842-54

29. Li S, Deng Z, Fu J, Xu C, Xin G, Wu Z, et al. Spatial compartmentalization specializes the function of Aurora a and Aurora B. J Biol Chem. 2015;290(28): 17546-58.

30. Hata T, Furukawa T, Sunamura M, Egawa S, Motoi F, Ohmura N, et al. RNA interference targeting aurora kinase a suppresses tumor growth and enhances the taxane chemosensitivity in human pancreatic cancer cells. Cancer Res. 2005;65(7):2899-905.

31. Scharer CD, Laycock N, Osunkoya AO, Logani S, McDonald JF, Benigno BB, et al. Aurora kinase inhibitors synergize with paclitaxel to induce apoptosis in ovarian cancer cells. J Transl Med. 2008;6:79.

32. Zumbar CT, Usubalieva A, King PD, Li X, Mifsud CS, Dalton HM, et al. The CNS penetrating taxane TPI 287 and the AURKA inhibitor alisertib induce synergistic apoptosis in glioblastoma cells. J Neuro-Oncol. 2018;137(3):481-92

33. Fu S, Li Y, Huang J, Liu T, Hong Z, Chen A, et al. Aurora kinase inhibitor VE 465 synergistically enhances cytotoxicity of carboplatin in ovarian cancer cells through induction of apoptosis and downregulation of histone 3 . Cancer Biol Ther. 2012;13(11):1034-41.

34. Sak M, Zumbar CT, King PD, Li X, Mifsud CS, Usubalieva A, et al. Cytotoxic synergy between alisertib and carboplatin versus alisertib and irinotecan are inversely dependent on MGMT levels in glioblastoma cells. J Neuro-Oncol. 2019;143(2):231-40.

35. Webber K, Friedlander M. Chemotherapy for epithelial ovarian, fallopian tube and primary peritoneal cancer. Best Pract Res Clin Obstet Gynaecol. 2017:41:126-38

\section{Publisher's Note}

Springer Nature remains neutral with regard to jurisdictional claims in published maps and institutional affiliations.

Ready to submit your research? Choose BMC and benefit from:

- fast, convenient online submission

- thorough peer review by experienced researchers in your field

- rapid publication on acceptance

- support for research data, including large and complex data types

- gold Open Access which fosters wider collaboration and increased citations

- maximum visibility for your research: over $100 \mathrm{M}$ website views per year

At $\mathrm{BMC}$, research is always in progress.

Learn more biomedcentral.com/submissions 